\title{
Effects of a standardized $40 \%$ ellagic acid pomegranate (Punica granatum L.) extract on seminiferous tubule histopathology, diameter, and epithelium thickness in albino Wistar rats after heat exposure
}

\author{
Budi Utomo ${ }^{1}$, Nurfitri Rahmah Daningtia ${ }^{2}$, Gandul Atik Yuliani ${ }^{3}$ and Wiwik Misaco Yuniarti ${ }^{4}$
}

1. Department of Reproduction, Faculty of Veterinary Medicine, Universitas Airlangga. Jl. Mulyorejo, Kampus $C$ Unair, Surabaya 60115, Indonesia; 2. Faculty of Veterinary Medicine, Universitas Airlangga. Jl. Mulyorejo, Kampus Unair, Surabaya 60115, Indonesia; 3. Department of Basic Veterinary Science, Faculty of Veterinary Medicine, Universitas Airlangga. Jl. Mulyorejo, Kampus C Unair, Surabaya 60115, Indonesia; 4. Department of Veterinary Clinics, Faculty of Veterinary Medicine, Universitas Airlangga. Jl. Mulyorejo, Kampus C Unair, Surabaya 60115, Indonesia.

Corresponding author: Budi Utomo, e-mail: budi_reprovet@yahoo.com

Co-authors: NRD: nurfitrirahmah@gmail.com, GAY: gandulatik@yahoo.com, WMY: wiwikmisaco@yahoo.com Received: 18-04-2019, Accepted: 08-07-2019, Published online: 17-08-2019

doi: 10.14202/vetworld.2019.1261-1265 How to cite this article: Utomo B, Daningtia NR, Yuliani GA, Yuniarti WM (2019) Effects of a standardized $40 \%$ ellagic acid pomegranate (Punica granatum L.) extract on seminiferous tubule histopathology, diameter, and epithelium thickness in albino Wistar rats after heat exposure, Veterinary World, 12(8): 1261-1265.

\begin{abstract}
Background and Aim: It has long been known that the spermatogenic tissue is very sensitive to temperatures higher than its physiologic temperature and causing cessation of activity and resulting in sterility. This study investigated the effect of a standardized $40 \%$ ellagic acid extract of pomegranate on the histopathology, diameter, and epithelial thickness of seminiferous tubules in albino rats exposed to heat.

Materials and Methods: Twenty-five male albino Wistar rats were randomized at 7-8 months of age to five treatment groups. Group C was not treated; Group T0 was treated with $0.5 \%$ of Na carboxymethyl cellulose (CMC) $2 \mathrm{ml} / \mathrm{day}$ and exposed to heat. T1, T2, and T3 were treated with 75, 150, and $300 \mathrm{mg} / \mathrm{kg} / \mathrm{day}$ of a standardized $40 \%$ ellagic acid extract of pomegranate (Punica granatum L.), respectively. The animals were orally administered $\mathrm{Na}$ CMC or pomegranate extract and were exposed to sunlight for $15 \mathrm{~min}$ at $40^{\circ} \mathrm{C}-42^{\circ} \mathrm{C}$ for 14 days. The animals were sacrificed on day 15 and the testes were removed for histological evaluation and measurement of seminiferous tubule diameter and epithelium thickness.

Results: The diameter of seminiferous tubules from rats exposed to heat and treated with $300 \mathrm{mg} / \mathrm{kg} / \mathrm{day}$ pomegranate extract was larger and the epithelia thicker than those in the other groups $(\mathrm{p}<0.05)$. The protective effects of the standardized $40 \%$ ellagic acid extract may have been mediated by its antioxidant activity.

Conclusion: Compared with controls, administration of $300 \mathrm{mg} / \mathrm{kg} / \mathrm{day}$ of a standardized $40 \%$ ellagic acid extract of P. granatum L. for 14 days increased seminiferous tubule diameter and epithelium thickness in albino Wistar rats exposed to heat.
\end{abstract}

Keywords: diameter, epithelium thickness, heat, pomegranate extract, seminiferous tubule.

\section{Introduction}

Male animals are considered infertile if conception does not occur after mating for 12 months or more. Infertility may be caused by decreased spermatozoa production or motility that reduces the number that reaches the ovum and is able to penetrate the egg membrane during fertilization [1]. Male reproductive function begins with spermatogenesis, the development of spermatozoa from spermatogonia, which is regulated by testosterone, follicle-stimulating hormone (FSH), and luteinizing hormone produced by Leydig and Sertoli cells in the seminiferous tubules of the testes [2]. Fertility depends on both the quality of

Copyright: Utomo, et al. Open Access. This article is distributed under the terms of the Creative Commons Attribution 4.0 International License (http://creativecommons.org/licenses/by/4.0/), which permits unrestricted use, distribution, and reproduction in any medium, provided you give appropriate credit to the original author(s) and the source, provide a link to the Creative Commons license, and indicate if changes were made. The Creative Commons Public Domain Dedication waiver (http://creativecommons.org/ publicdomain/zero/1.0/) applies to the data made available in this article, unless otherwise stated. spermatozoa the successful delivery of spermatozoa to ovum. In addition to hormones, spermatogenesis is influenced by factors that inhibit epididymal function, radiation, and increased temperature [1]. Heat exposure causes an imbalance of the production of free radicals and antioxidants, with an increase in free radicals resulting in oxidative stress [3].

Pomegranate (Punica granatum L.) is an ornamental plant that is rarely cultivated in Indonesia, where its potential benefits for treating male fertility are not appreciated. Pomegranate is a source of plant antioxidants high in polyphenols, anthocyanins, and Vitamin $\mathrm{C}$ that can prevent damage caused by oxidative stress and protects cell from free radicals [4]. Vitamin $\mathrm{C}$ has antioxidant activity that is synergistic with polyphenol antioxidants present in pomegranates such as anthocyanins, punicalagin, ellagic acid, and gallic acid in protecting cells from free radical damage. Pomegranates can maintain fertility by protecting seminiferous tubule cells from free radical damage [5]. Vitamin $\mathrm{C}$ deficiency can result in 
testicular tissue damage and reduction in the number of spermatogenic cells in seminiferous tubules, with consequent decreases in seminiferous tubule diameter, thickness of the seminiferous tubule epithelium, and testicle weight [6].

This study investigated the effect of a standardized $40 \%$ ellagic acid pomegranate $(P$. granatum $\mathrm{L}$.) extract on seminiferous tubule diameter and thickness in albino Wistar rats after exposure to heat stress.

\section{Materials and Methods}

\section{Ethical approval}

The study was conducted following ethical guidelines for the use of experimental animals and as approved by the ethics committee of the Faculty of Veterinary Medicine, Universitas Airlangga, Indonesia.

\section{Time and place}

This study was conducted from June to December 2017 at Pharmacology Laboratory, Faculty of Medicine and Veterinary Pathology Laboratory, and Faculty of Veterinary Medicine, Universitas Airlangga, Surabaya.

\section{Materials}

Powdered pomegranate extract (P. granatum L.) was standardized as $40 \%$ ellagic acid solution (Xi' an Bio-Technology Co. Ltd., Xi'an, China). Other reagents included hematoxylin and eosin stains, physiological saline, $30 \%, 50 \%, 70 \%, 80 \%, 95 \%$, and $100 \%$, ethanol, $5 \% \mathrm{Na}$ carboxymethyl cellulose (CMC), 10\% buffered formalin, xylol, paraffin, glycerin, balsam, ether, animal feed, and drinking water. The tools used in this study include electric scales, spoons, pharmacy paper, label paper, plastic, Erlenmeyer flasks, Petri dishes, stirrers, food pipes, cage cleaning tools, masks, gloves, food and drink containers, surgical instruments (tweezers, scalpel, blade, and scissors), object-glass, pipettes, hot plates, coverslips, and a light microscope (Nikon Eclipse E 100 LED) were used.

\section{Experimental procedures}

Rats were weighed at the beginning and the end of experimental procedures and were sacrificed by exposure to ether. Testes and seminiferous tubule were dissected, weighed, cleared of adhering connective tissue, and assayed immediately. The testes were weighed and the seminiferous tubule weight, length, and thickness were measured. The diameter and thickness of seminiferous tubule from five rats per treatment were measured using an ocular micrometer in a light microscope (Nikon Eclipse E-100) and the average size of seminiferous tubule and germinal cell layer thickness was calculated. Seminiferous tubule diameter $(\mu \mathrm{m})$ was measured by ocular micrometer and results were given as average. One of testis from each rat was fixed in $10 \%$ formalin for histopathological examination. About 25 white male Wistar rats randomly allocated at 7-8 months of age to five study groups. Group C was not treated. Group T0 was treated with $0.5 \%$ of $\mathrm{Na}$ CMC $2 \mathrm{ml} /$ day, Group T1 was treated with $75 \mathrm{mg} / \mathrm{kg}$ /day pomegranate extract, Group T2 was treated with $150 \mathrm{mg} / \mathrm{kg} / \mathrm{day}$, and Group T3 was treated with $300 \mathrm{mg} / \mathrm{kg} /$ day pomegranate extract. The animals in Groups T0-T3 were exposed to temperatures of $40^{\circ} \mathrm{C}-42^{\circ} \mathrm{C}$ produced by exposure to $15 \mathrm{~min}$ of sunlight. The animals were treated for 14 days.

\section{Histopathological examination}

Testis and seminiferous tubule tissue were fixed in $10 \%$ buffered formalin for $24 \mathrm{~h}$. Serial tissue sections were processed by standard histological techniques and stained with for observation by light microscopy with a Nikon Eclipse E-100 Microscope. Five randomly selected fields of view in each slide of the histopathological tissue preparations were scored at $100 \times$.

\section{Statistical analysis}

The statistical analysis was performed by SPSS 20.0 software (IBM, USA). The results were presented as means value $( \pm$ SD). One-way analysis of variance and post hoc analysis with Duncan's test for multiple comparisons was used to compare each group and data among the groups, respectively. $\mathrm{p}<0.05$ was considered statistically significant.

\section{Results and Discussion}

Testis tissue from control Group (C) rats had a normal microscopic structure. The diameter of the seminiferous tubules in Group T0 rats was significantly different from that in Groups C, T1, T2, and $\mathrm{T} 3$ rats $(\mathrm{p}<0.05)$. The diameters of Group $\mathrm{C}$ and Group T1 were not significantly different $(\mathrm{p}>0.05)$, but both were different from the diameters of the tubules in Groups T0, T2, and T3 $(p<0.05)$. The diameters of the tubules in Group T2 and Group T3 were significantly different. The smallest mean seminiferous tubule diameter $(261.85 \pm 15.85 \mu \mathrm{m})$ was seen in Group T0 group and the largest $(335.93 \pm 25.85 \mu \mathrm{m})$ in Group T3 (Figure-1 and Table-1). The thickness of the seminiferous tubule epithelium in Group C, which was not treated, and that in Group T2, which was exposed to heat and $150 \mathrm{mg} . \mathrm{kg} /$ day pomegranate extract, was not significantly different. The difference in the tubule epithelium thickness in Group T1 (heat and $75 \mu \mathrm{m} / \mathrm{kg} /$ day extract) and Group T2 (heat and $150 \mathrm{mg} / \mathrm{kg} / \mathrm{day}$ ) was not significantly different $(p>0.05)$. The seminiferous tubular epithelium in T3 was the thickest compared with the control group and the other treatments $(p<0.05$, Figure- 2 and Table- 1$)$. Heat exposure decreased the thickness of the seminiferous tubule epithelium, and the change was primarily caused by a loss of germ cells. Spermatogenic cells in the seminiferous tubule epithelium and Leydig cells in interstitial areas were markedly prominent in Group T3 rats. The reduction of the seminiferous tubule diameter in the Group T0 rats indicates that heat caused atrophy of the tubules and led to morphological changes and disturbed spermatogenesis in the testis. The results are consistent with a previous 

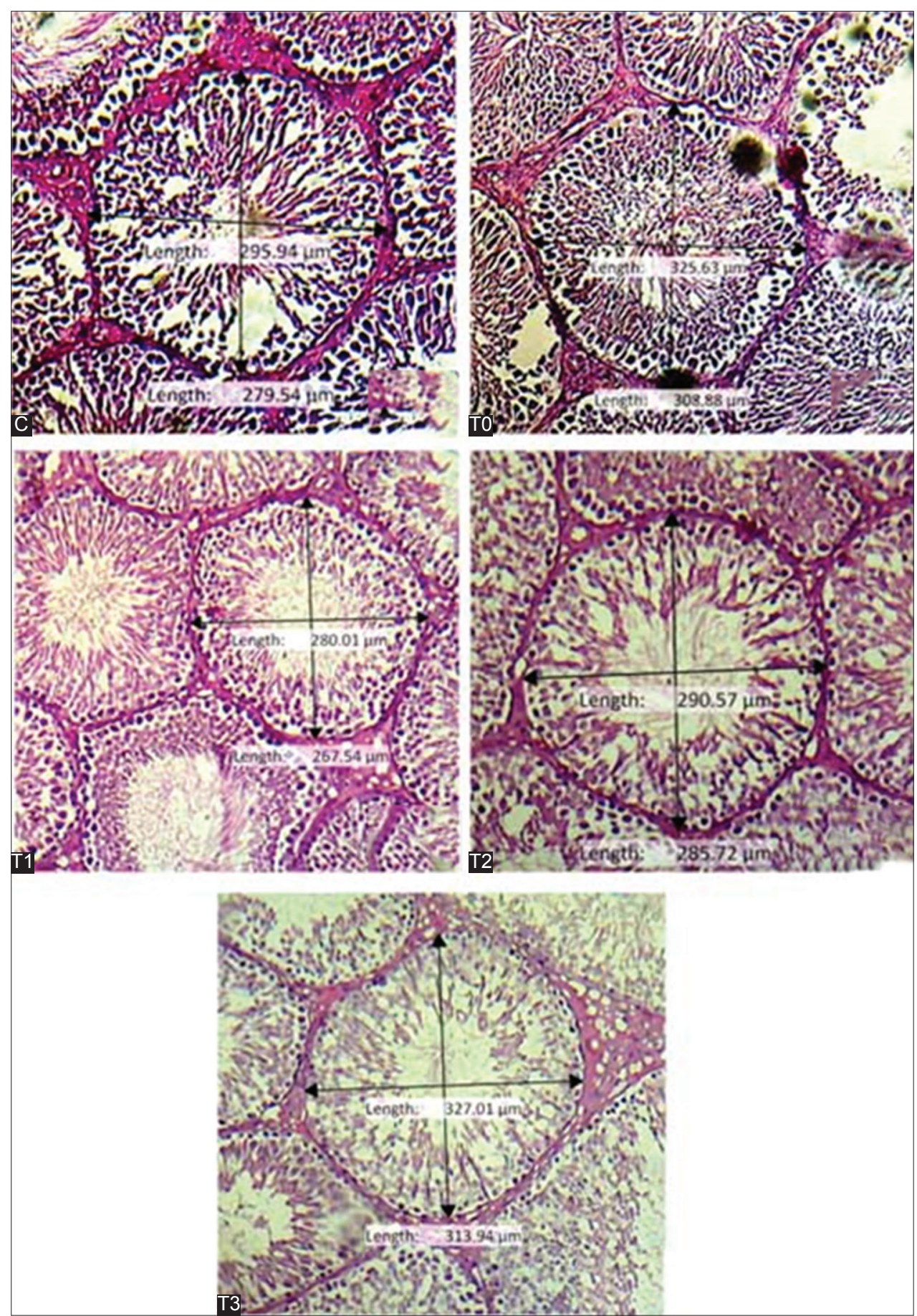

Figure-1: Histopathology and diameter of seminiferous tubules from Groups C, T0, T1, T2, and T3 (100×, hematoxylin-eosin staining).

report of a positive relationship between seminiferous tubules diameter and spermatogenesis activity [7].

The study showed that the treatment of the rats within Groups T1, T2, and T3 with pomegranate extract significantly increased the diameter of the seminiferous tubules and the thickness of the tubule epithelium compared with Group T0 rats treated with heat and $\mathrm{Na} \mathrm{CMC}$. The effects were probably the result of the antioxidant properties of the pomegranate extract. In another study, exposure to cigarette smoke led to reductions in seminiferous tubule diameter and epithelial thickness that were inhibited by honey supplementation. It was suggested that the protective effect was mediated by the antioxidant activity of honey [8]. Cyclophosphamide-induced reduction in the spermiogenesis index, tubule differentiation index, serum testosterone, and testis weight has been found to be partially returned to normal by an extract of Crataegus monogyna with known antioxidant activity [9].

Treatment with the pomegranate extract resulted in significant increases in seminiferous tubule diameter compared with the Groups $\mathrm{C}$ and $\mathrm{T} 0$. The largest increase was seen in Group T3, which was given $300 \mathrm{mg} . \mathrm{kg} /$ day for 14 days. The standardized $40 \%$ ellagic acid extract of $P$. granatum L. has antioxidant 
activity. Antioxidants stabilize free radicals by satisfying electron deficiencies and inhibiting the chain reaction of free radical formation that causes cell damage during heat exposure. Administration of the standardized pomegranate extract at $300 \mathrm{mg} / \mathrm{kg}$ may have suppressed free radical formation. The resulting prevention of the damage of cell membranes and preservation of hormone receptors involved in the promotion of spermatogenesis has been shown to result in an increase in spermatogenic cells [10]. Increase in the spermatogenic and Sertoli cells in the tubular epithelium results in narrowing of seminiferous tubule lumen, thickening of seminiferous epithelium, and increase the diameter of the seminiferous tubule [11]. According to Franca and Russell [12], there is a positive relation between tubular diameter and the spermatogenic activity. The treatment with all of the concentrations of pomegranate increased tubular

Table-1: Seminiferous tubule diameter and epithelium thickness.

\begin{tabular}{lcc}
\hline Treatment group & $\begin{array}{c}\text { Diameter, } \boldsymbol{\mu m} \\
\text { (mean } \pm \text { SD) }\end{array}$ & $\begin{array}{c}\text { Epithelium } \\
\text { thickness, } \boldsymbol{\mu m} \\
\text { (mean } \pm \text { SD) }\end{array}$ \\
\hline C (no treatment) & $261.85^{\mathrm{b}} \pm 15.85$ & $86.27^{\mathrm{b}} \pm 10.44$ \\
T0 (Na CMC 0.5/day) & $221.43^{\mathrm{a}} \pm 10.50$ & $78.11^{\mathrm{a}} \pm 14.24$ \\
T1 $(75 \mathrm{mg} / \mathrm{kg} /$ day) & $253.59^{\mathrm{b}} \pm 18.73$ & $80.24^{\mathrm{a}} \pm 11.69$ \\
T2 $(150 \mathrm{mg} / \mathrm{kg} /$ day $)$ & $300.17^{\mathrm{c}} \pm 29.84$ & $87.75^{\mathrm{b}} \pm 14.99$ \\
T3 $(75 \mathrm{mg} / \mathrm{kg} /$ day) & $335.93^{\mathrm{d}} \pm 25.85$ & $95.9^{\mathrm{c}} \pm 8.49$ \\
\hline
\end{tabular}

Superscripts in the same column indicate significant differences following by Duncan's MCT $(p<0.05)$. $\mathrm{SD}=$ Standard deviation diameter and thickness of the epithelium. The results were differing significantly from the control group, suggesting that there was improvement with pomegranate given to the treatment groups. The dominant antioxidant compound contained in $P$. granatum $\mathrm{L}$. extract is anthocyanin, which is likely to influence hormonal regulation of FSH, luteinizing hormone and testosterone, thereby affecting the growth and development of and Sertoli cells and spermatogonia $[13,14]$.

A significant increase in spermatogenic cells in Group T3 compared with Groups C and T0 resulted in corresponding significant increase in the thickness of the seminiferous tubule epithelium and diameter. The increases were consistent with anthocyanin reduction of oxidative stress caused by heat exposure and maintenance of spermatogenic cells by inhibition of enzyme damage to maintain normal spermatogenesis. Increased epithelium thickness has been associated with increased numbers of Sertoli and spermatogenic cells [15]. The antioxidant activity of anthocyanin has been attributed to the donation of a single electron to oxidant molecules and thus increasing the number of spermatozoa [16].

The decrease in seminiferous tubule epithelium thickness in the T0 comparison group resulted from loss of Sertoli and spermatogenic cells or spermatogenesis inhibition [17] as well as the possibility of germinal cell apoptosis. Apoptosis may occur spontaneously in seminiferous epithelium or as a response to various factors including chemotherapy agents, high temperature, and hormone activity [18]. The study
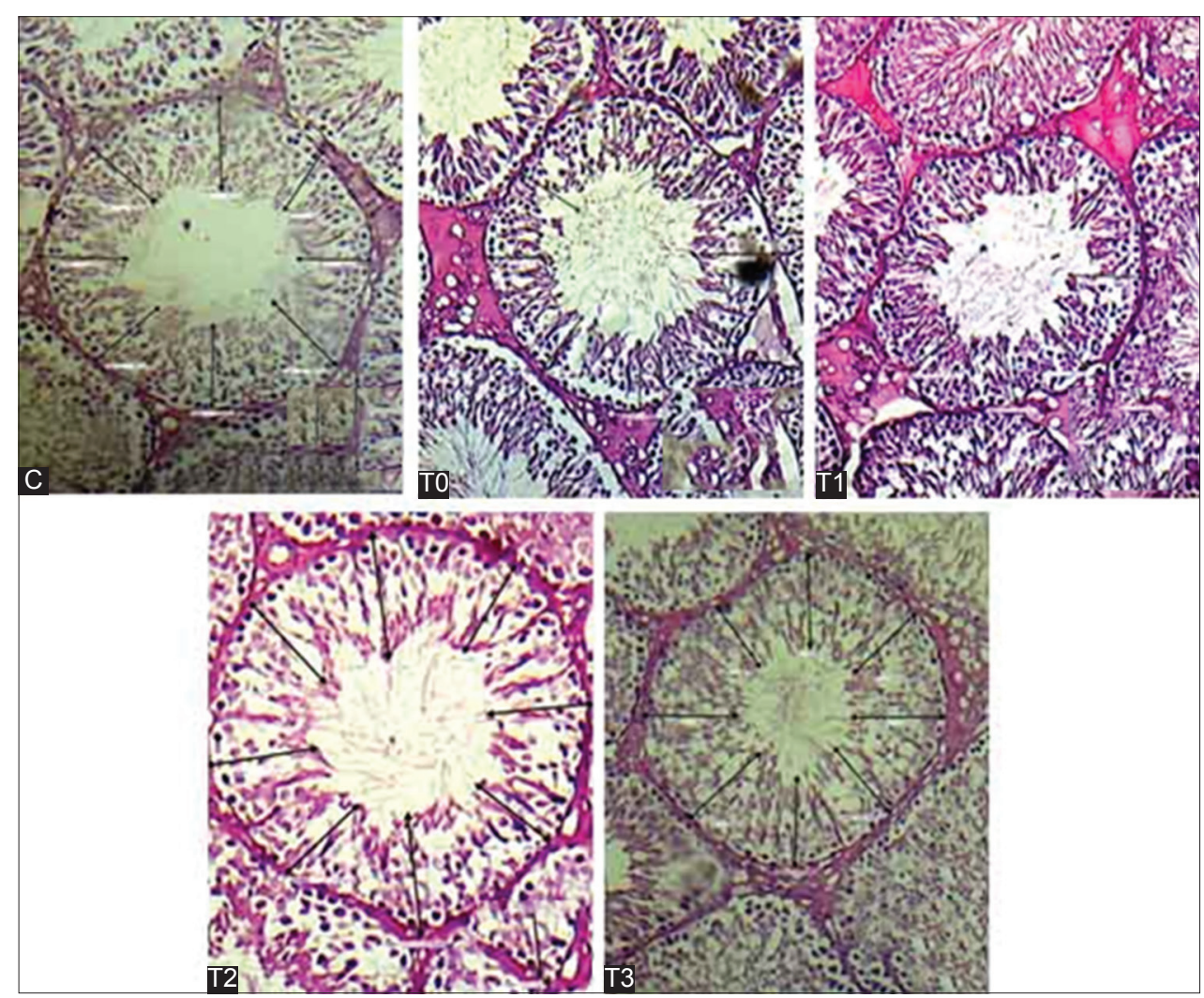

Figure-2: Histopathology and epithelial thickness of seminiferous tubules in Groups C, T0, T1, T2, and T3 (100x, hematoxylin-eosin staining). 
results show that $300 \mathrm{mg} / \mathrm{kg} /$ day of the pomegranate extract promoted increases in the seminiferous tubule diameter and epithelial thickness, leading to increased efficiency of spermatogenesis.

\section{Conclusion}

A standardized $40 \%$ ellagic acid extract of pomegranate $(P$ granatum L.) at a dose of $300 \mathrm{mg} / \mathrm{kg} /$ day increased seminiferous tubule diameter and epithelium thickness in Wistar albino rats following exposure to heat.

\section{Authors' Contributions}

BU and NRD carried out the main study procedures, WMY performed the histopathological analysis of the testis, and GAY performed the statistical analysis. All authors have read and approved the final version of the manuscript.

\section{Acknowledgments}

The authors thank the Faculty of Veterinary Medicine, Universitas Airlangga, Surabaya, Indonesia, for providing the facilities and resources to conduct this research. This study was funded by the authors.

\section{Competing Interests}

The authors declare that they have no competing interests.

\section{Publisher's Note}

Veterinary World remains neutral with regard to jurisdictional claims in published institutional affiliation.

\section{References}

1. Short, R.E., Bellows, R.A., Staigmiller, R.B., Berardinelli, J.G. and Custer, E.E. (1990) Physiological mechanisms controlling anestrus and infertility in postpartum beef cattle. J. Anim. Sci., 68(3): 799-816.

2. Suresh, R. and Gerhard, F.W. (2004) Endocrine control of spermatogenesis: Role of FSH and LH/testosterone. Spermatogenesis, 4(2): 1-15.

3. Rozan, P., Hidalgo, S., Nejdi, A., Bisson, J.F., Lalonde, R. and Messaoudi, M. (2007) Preventive antioxidant effects of cocoa polyphenolic extract on free radical production and cognitive performances after heat exposure in Wistar rats. J. Food Sci., 72(3): 203-206.

4. Pilar, L., Forner-Giner, M.A., Nuncio-Jauregui, N. and Hernandez, A. (2016) Polyphenolic compounds, anthocyanins and antioxidant activity of nineteen pomegranate fruits: A rich source of bioactive compounds. J. Funct. Foods, 23(1): 628-636.

5. Zeweil, H.S., ElNagar, S., Zahran, S.M., Ahmed, M.H. and
El-Gindy, Y. (2013) Pomegranate peel as a natural antioxidant boosts bucks' fertility under Egyptian summer conditions. World Rabbit Sci., 21(1): 33-39.

6. Ayinde, O.C., Sunday, O. and Rita, A.O. (2012) Influence of Vitamin C and Vitamin E on testicular zinc content and testicular toxicity in the lead exposed albino rats. BMC Pharmacol. Toxicol., 13(17): 2-8.

7. Lue, Y., Amiya, P., Sinha, H., Christina, W., Michael, I., Andrew, L. and Ronald, S.S. (2000) Testicular heat exposure enhances the suppression of spermatogenesis by testosterone in rats: The "two-hit" approach to male contraceptive development. Endocrinology, 141(4): 1414-1424.

8. Mohamed, M., Sulaiman. S.A., Jaafar, H. and Sirajudeen, K.N.S. (2011) Antioxidant protective effect of honey in cigarette smoke-induced testicular damage in rats. Int. J. Mol. Sci., 12(9): 5508-5521.

9. Shalizar, J.A., Hassanzadeh, S.H. and Malekinejad, H. (2011) Chemoprotective effect of Crataegus monogyna aqueous extract against cyclophosphamide-induced reproductive toxicity. Vet. Res. Forum, 2(4): 266-273.

10. Al-Olayan, E.M., Manal, F.E., Dina, M.M. and Ahmed, E.A. (2014) Protective effects of pomegranate (Punica granatum) juice on testes against carbon tetrachloride intoxication in rats. BMC Complement. Altern. Med. 14(1): 164-171.

11. Triphatil, U.K., Shivani, C.A., Kumaresan, M.K., Aslam, S.K.M., Samiksha N., Manimaran, A., Mohanty, T.K. and Savita Y. (2015) Morphometric evaluation of seminiferous tubule and proportionate numerical analysis of sertoli and spermatogenic cells indicate differences between crossbred and purebred bulls. Vet. World, 8(5): 645-650.

12. Franca, L.R. and Russell, L.D. (1998) The testis of domestic mammals. In: Martinez-Gracia, F and Regadera, J., editors. Male Reproduction a Multidisciplinary Overview. Churchill Communications, Madrid. p198-219.

13. Esmaeilinezhad, Z., Babajafari, S., Sohrabi, Z., Eskandari, M.H., Amooee, S. and Barati-Boldaji, J. (2019) Effect of synbiotic pomegranate juice on glycemic, sex hormone profile and anthropometric indices in PCOS: A randomized, triple-blind, controlled trial. Nutr. Metabol. Cardiovasc. Dis., 29(2): 201-208.

14. Gustavo, M.E., Luciana, A.R. and da Silveira, L.E. (2014) Mechanisms of hormonal regulation of sertoli cell development and proliferation: A key process for spermatogenesis. Curr. Mol. Pharmacol., 7(2): 96-108.

15. Khojasteh, S.M.B., Reihaneh, J.K., Maryam, H. and Elham, Y. (2016) A review on medicinal plants used for improvement of spermatogenesis. Biol. Med., 2(4): 4, 1-7.

16. Kahkonen, M.P., and Marina, H. (2003) Antioxidant activity of anthocyanins and their aglycons. J. Agric. Food Chem., 51(3): 628-633.

17. Ann, S., Hild, J.R., Reel, J.M., Larner, R. and Blye, P. (2001) Disruption of spermatogenesis and sertoli cell structure and function by the indenopyridine CDB-4022 in Rats. Biol. Reprod., 65(6): 1771-1779.

18. Yin, Y., Stahl, B.C., DeWolf, W.C. and Morgentaler, A. (1998) Heat-induced testicular apoptosis occurs independently of hormonal depletion. Apoptosis, 3(4): 281-288. 